\title{
Editorial
}

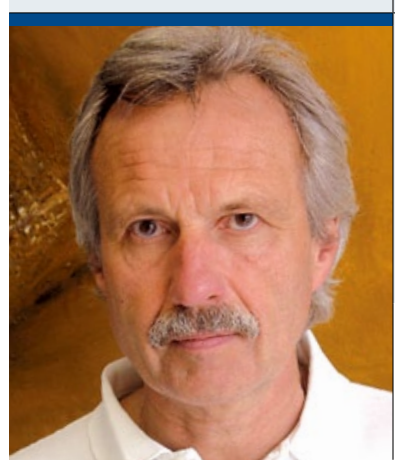

"Der Name Patientenrechteschutzgesetz suggeriert, dass ein Schutzwall notwendig ist, um den Patienten vor ärztlicher Willkür abzuschirmen."

\section{Wacht auf, Verdammte dieser Erde!}

$P_{t a t a n}^{a}$ atienten, ihr Entrechteten, Geschundenen, Getretenen, willfährigen Opfer einer korrupten, skrupellosen, entmenschlichten Ärzteschaft ohne jedes Verantwortungs- und Mitgefühl! Einer Kaste, deren Behandlungsfehler Methode haben, generell Ursache jeder erfolglosen Heilung sind und zum Erhalt der ärztlichen Aura grundsätzlich vertuscht werden. Kurzum, Ärzte sind eine Kaste, deren Spektrum im Spiegel medienwirksam als „Pfuscher oder Retter" umrissen wird.

\section{Der Kranke braucht den Arzt}

Die Medizin zählt zu den ältesten Errungenschaften der menschlichen Kultur. Die von Menschen für Menschen geschaffene Heilkunst ist die Antwort auf die elementarste Beeinträchtigung des Menschen: das Kranksein. Nach Seneca ist dies ein $\mathrm{Zu}-$ stand aus „Intermissio voluptatum, dolor corporis und metus mortis“. Schmerz und die Angst vor dem Tod haben die medizinische Wissenschaft und den Beistand durch den Arzt ins Leben gerufen, weil der kranke Mensch in seiner Not sie braucht. Ein Anrecht auf Heilung oder Entschädigung bei Misserfolg lässt sich daraus nicht ableiten. „Nach dem $\mathrm{Na}$ turinstinkt wird dem Menschen der Arzt der wichtigste Mann sein, weil dieser ihm sein Leben fristet" und trotz des Versprechens der künftigen Glückseligkeit durch die Geistlichkeit „sehnlich wünscht, von dem Arzt in diesem Jammertal immer noch einige Zeit erhalten zu werden.“ Dies schrieb Immanuel Kant in seiner Schrift über den Streit der Fakultäten.

\section{Medizin ist kein Konsumgut}

Was soll ein Patientenrechteschutzgesetz? Allein der Name konterkariert das angeblich so kostbare und zerbrechliche Vertrauensverhältnis zwischen Arzt und Patient, das gehütet und gepflegt werden sollte. Da wird suggeriert, dass ein Schutzwall notwendig ist, um den Patienten vor ärztlicher Willkür abzu- schirmen. Als müsse biedere, gutgläubige Kundschaft vor hinterlistigen Verkäufern maroder Ware geschützt werden. Wenn Wolfgang Zöller (CSU) sich freut, der Patient werde per Gesetz ,vom Bittsteller zum Partner“ oder Marlies Volkmer (SPD) kritisiert, die Mitwirkungsrechte von Patienten seien nicht ausreichend berücksichtigt, zeigt dies, dass beide nie krank gewesen sind. Der leidende Kranke ist in seiner Not immer Bittsteller und zur Mitwirkung niemals fähig. Ihm ist durch kein Gesetz der Welt zu helfen. Er muss dem Mitmenschen vertrauen, den die Ausbildung befähigt und die Mitmenschlichkeit motiviert, ihm „nach bestem Wissen und Können“ (Hippokrates) zu helfen. Befindlichkeitsstörungen mögen einer gesetzlichen Konsumentenregelung zugänglich sein: Perfektion beim Heilen und Lindern, 24 Stunden am Tag, sieben Tage in der Woche. Natürlich ohne Risiko oder Schaden! Weniger als maximaler Erfolg wird verklagt.

\section{Der Patient - Gegner des Arztes}

Was soll erreicht werden? Eine wohlfeile Lösung, an Entschädigungen zu kommen? Am liebsten über einen Entschädigungsfond!? Bei Auszahlung ist damit auch gleich ohne Widerspruchsmöglichkeit des Betroffenen sein Fehlverhalten festgestellt. Abgelehnt! Dann eben über den Hebel der vollständigen Dokumentation. Lücken sind vor Gericht eine Beweiserleichterung für den Patientenanwalt. Aufgemerkt! Der Patient wird nicht mehr als Hilfesuchender wahrgenommen, sondern als potenzieller Gegner. O tempora, o mores!

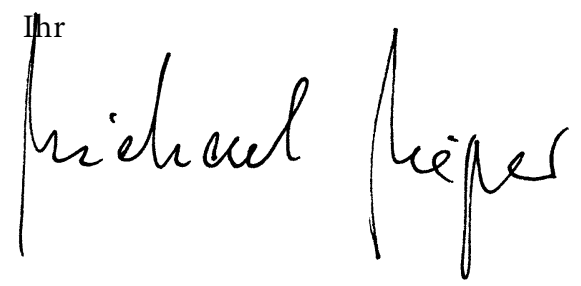

